\title{
Review and Preliminary Investigation into Fuel Loss from Cermets Composed of Uranium Nitride and a Molybdenum-Tungsten Alloy for Nuclear Thermal Propulsion Using Mesoscale Simulations
}

\author{
JACOB HIRSCHHORN,${ }^{1}$ FLOYD HILTY, ${ }^{1}$ MICHAEL R. TONKS $\mathbb{}$ (i), ${ }^{1,3}$ \\ and JHONATHAN ROSALES ${ }^{2,4}$ \\ 1.-Department of Materials Science and Engineering, University of \\ Florida, Gainesville, FL, USA. 2.-Marshall Space Flight Center, National Aeronautics and \\ Space Administration, Huntsville, AL, USA. 3.-e-mail: michael.tonks@ufl.edu. \\ 4.—e-mail: jhonathan.rosales@nasa.gov
}

A ceramic-metal composite (cermet) of uranium nitride (UN) particles embedded in a tungsten-molybdenum (W/Mo) alloy matrix is being considered as reactor fuel for nuclear thermal propulsion (NTP). One possible issue is the loss of fissile uranium atoms during reactor operation. We begin by reviewing historical data that suggest that a likely mechanism for fuel loss is transport of free uranium along metal grain boundaries and through cracks to free surfaces. We then employ simple two-dimensional (2D) mesoscale simulations to provide insights into crack formation and free uranium transport in a W/ Mo-UN cermet. Phase-field fracture simulations show that cracks form during cooling at the fuel-matrix interface and then within the fuel particles. Transport simulations show that cracks at the fuel-matrix interface and within the fuel accelerate fuel loss. Mechanical and diffusion data are needed for UN and W/Mo alloys to make these preliminary predictions more accurate.

\section{INTRODUCTION}

As mankind continues to explore our solar system further and further from Earth, an alternative method of propulsion to chemical rockets is needed. One such method is nuclear thermal propulsion (NTP). In NTP, a nuclear reactor is used to superheat hydrogen gas, which is then expelled through a nozzle to provide thrust, as illustrated in Fig. 1. The gas also serves to cool the reactor, producing a temperature change in the axial direction of over $2000 \mathrm{~K}^{1}{ }^{1}$ During operation, such a reactor would undergo multiple restart and short-burn propulsion cycles $^{2,3}$ for a combined burn time of under $2 \mathrm{~h}$ at very high temperature $(2800 \mathrm{~K}$ to $3000 \mathrm{~K}){ }^{2,4} \mathrm{In}$ addition, the reactor may operate at low power and temperature between propulsion cycles to supply electrical power to the spacecraft ${ }^{2,4}$ (hundreds of

(Received June 1, 2021; accepted August 24, 2021;

published online September 21, 2021)
$\mathrm{kW}_{\mathrm{e}}$ to $1 \mathrm{MW}_{\mathrm{e}}$ ). The reactor materials would experience long-term radiation damage at low temperature and low neutron flux with short bursts of high temperature and high neutron flux. Thus, the conditions experienced by materials in NTP reactors differ substantially from those experienced in power reactors.

NTP is not a new concept. Researchers first began exploring the use of nuclear reactors for rocket propulsion in the late $1940 \mathrm{~s}$, and active development for space exploration started in the USA in the 1960 s as part of the Rover/Nuclear Engine for Rocket Vehicle Application (NERVA) program. ${ }^{5-7}$ Several prototypes were tested, but development ended in the early 1970s. Study of NTP engines reemerged in 2015 when NASA's Nuclear Cryogenic Propulsion Stage (NCPS) project evolved into the NTP project. ${ }^{5}$ In the NTP project, research is ongoing to determine the optimal reactor design and fuel type for NTP. ${ }^{8}$ 


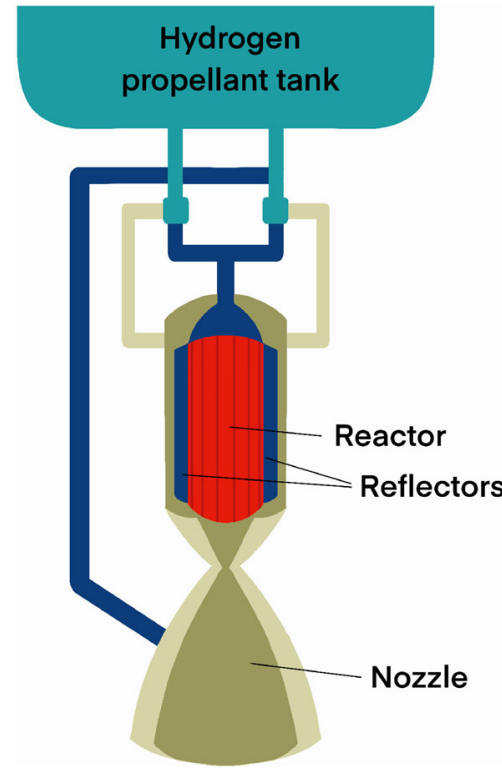

Fig. 1. Schematic of an NTP reactor, where hydrogen gas is superheated by a reactor and then expelled through a nozzle to generate thrust.

Two fuel types are being considered for NTP reactors: (1) a ceramic-ceramic composite (cercer) in which fuel particles are embedded in a ceramic matrix and (2) a ceramic-metal composite (cermet) in which fuel particles are embedded in a metal matrix. $^{8}$ Early research used cermet fuel, ${ }^{9}$ as well as a carbide fuel embedded in a graphite matrix; ${ }^{10}$ the focus of this work is on cermet fuel.

Early cermet concepts had highly enriched uranium dioxide $\left(\mathrm{UO}_{2}\right)$ embedded in a tungsten (W) matrix, and most of the published data on NTP cermet fuel are for this fuel type. ${ }^{9}$ Cermet concepts under development now use low-enriched uranium, which necessitates a move to an alternative fuel type with higher uranium density. Uranium nitride (UN) has a uranium density that is $40 \%$ larger than $\mathrm{UO}_{2}$ and a high enough melting temperature (3078 $\mathrm{K})$ to remain solid at the operating temperatures encountered during the propulsion cycles. Tungsten has a high neutron cross-section, which will lower the reactor efficiency. Therefore, molybdenum (Mo) or a W-Mo alloy, which have lower neutron crosssections, are being considered for the metal matrix material. ${ }^{8}$ Figure 2 shows a cermet fuel element with 60 vol.\% uncoated UN angular powder particles in a refractory metal matrix recently fabricated from a mixture of Mo and $\mathrm{W}$ powders at NASA Marshal Space Flight Center (MSFC).

NTP fuel design and fabrication must be optimized to advance the technology towards use in space exploration. However, the design space is large, with many design considerations, fabrication parameters, and material choices. Experimental studies must play a critical role in this optimization process. However, experiments are complicated by safety concerns and by the extreme conditions that

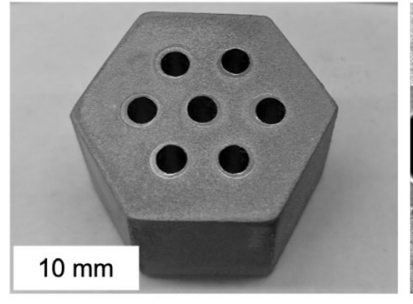

(a)

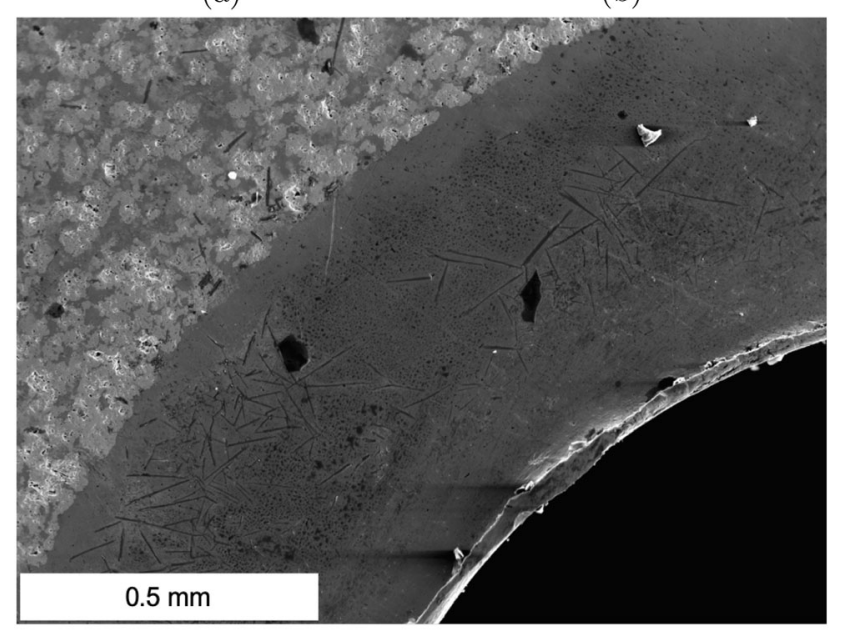

(c)

Fig. 2. Example of a W/Mo-UN fuel element: (a) the full fuel element with seven coolant channels, and (b, c) magnified views of the fuel element after exposure to hot hydrogen. In the fuel element, Mo cladding was used around the coolant channels, as seen in (b) and (c). These samples were recently fabricated at NASA MSFC.

will be experienced by the fuel during operation. Facilities that can approach these conditions are rare and expensive.

Modeling and simulation, however, can be used to shrink the design space and to design more targeted experiments. A recent paper ${ }^{11}$ demonstrated how a multiscale fuel performance modeling approach developed to model power reactors ${ }^{12}$ can be leveraged to quickly develop modeling capabilities for NTP reactors. Mesoscale simulations are used to determine effective macroscale material properties and microstructure changes within the fuel, using properties from experiments and from atomic-scale simulations. The mesoscale simulation results are then used to develop models of the structureevolution and structure-property relationships of the fuel.

The Nuclear Energy Advanced Modeling and Simulation (NEAMS) program has developed tools for this approach: the mesoscale nuclear materials tool MARMOT ${ }^{13,14}$ and the macroscale fuel performance tool BISON. ${ }^{15,16}$ Sessim and Tonks ${ }^{11}$ showed how existing capabilities in MARMOT and BISON can be used to model NTP fuel performance, although they only used the multiscale approach to determine the effective thermal conductivity of fresh $\mathrm{W}-\mathrm{UO}_{2}$ cermet fuel. Tucker et al. ${ }^{17}$ recently 
illustrated how lower-length-scale methods such as density functional theory (DFT) and discrete dislocation dynamics can play a critical role in this multiscale approach for modeling cermet fuel behavior. However, significant effort is still needed to use multiscale simulations to develop models that predict microstructure evolution in NTP fuel during operation and the resulting degradation of the fuel properties.

One significant form of microstructure change that is known to occur in NTP cermet fuel is fuel loss; when U-based materials are exposed to hot flowing hydrogen, $\mathrm{U}$ atoms vaporize and can escape with the propellant out of the nozzle. This loss of $U$ directly impacts the efficiency of the reactor and has the potential to decrease the chance of success of a long-term space mission. Fuel loss has been clearly documented for $\mathrm{W}-\mathrm{UO}_{2}$ cermet fuel ${ }^{9}$ and is anticipated to occur to some extent in W/Mo-UN cermet fuel. Several promising mitigation strategies have been developed for $\mathrm{W}-\mathrm{UO}_{2}$ cermets $^{9}$ and may be applicable to W/Mo-UN cermets. A predictive mesoscale model of W/Mo-UN cermet fuel loss would provide a means of investigating the efficacy of these mitigation strategies for the new fuel type. Such a mesoscale model could also lead to a macroscale model of fuel loss that could be used in a fuel performance model of NTP fuel, allowing the impact of fuel loss on overall fuel performance for an entire mission to be quantified, as well as the potential benefit of mitigation strategies.

The purpose of this work is to begin the development of a mesoscale model of fuel loss. We start in Sect. 2 by summarizing the current understanding of the mechanisms behind fuel loss in $\mathrm{W}-\mathrm{UO}_{2}$ cermets and potential mechanisms for fuel loss in W/Mo-UN cermets. One critical mechanism behind fuel loss is microcracking. Therefore, in Sect. 3, we present and apply a model of cracking due to thermal expansion mismatch in W/Mo-UN cermets. Another critical mechanism is the dissociation and transport of $U$ atoms. In Sect. 4, we develop and apply a model of this mechanism. Finally, we discuss potential ramifications of our results in Sect. 5 and conclude in Sect. 6.

\section{REVIEW OF FUEL LOSS IN CERMET FUEL}

In this section, we review the information regarding fuel loss in cermet fuels that is available in literature. We begin by summarizing what is known about fuel loss in $\mathrm{UO}_{2}$ cermets, with a focus on the mechanisms for fuel loss that have been identified and mitigation strategies that have been shown to be effective. We then discuss how these mechanisms can be translated to UN cermets and which mitigation strategies may still be applicable.

The majority of data on fuel loss in $\mathrm{UO}_{2}$ cermets were published in technical reports from NASA and various national laboratories from the 1960s to the early 1970 s. Unfortunately, these reports are often difficult to access. However, a review that was published in 2007 summarized much of this information9 and makes it much easier to access. We refer the reader to this publication for a more complete description of the thermal and radiation performance of $\mathrm{UO}_{2}$ cermets. The findings of the experiments and performance are summarized here, with a focus on the mechanisms for fuel loss and strategies that were shown to reduce it. Data are available for cermets of $\mathrm{UO}_{2}$ with the metal matrix composed of Mo, W, and rhenium (Re). These data come from experiments in which the material was raised to temperatures around $2300 \mathrm{~K}$ within minutes and held there for minutes to an hour. In some cases, they were then quickly cooled and reheated during multiple cycles.

Due to the repeated heating and cooling of the cermet fuel, the material repeatedly expands and contracts. However, the thermal expansion coefficients of $\mathrm{UO}_{2}$ and the metal matrix can be quite different, resulting in thermal strains during temperature changes. The thermal strains result in some creep but also cause cracking, especially at the interfaces between the fuel particles and the metal matrix. Thermal strain also results from the large axial temperature gradient that forms between the gas inlet and outlet locations. Finally, additional strain may result from fuel swelling due to fission product formation during reactor operation.

The most significant failure mode seen in $\mathrm{UO}_{2}$ cermets is the loss of fissile fuel. The mechanism for the fissile fuel loss depends on the location of the fuel in the metal matrix. When $\mathrm{UO}_{2}$ is at the surface of the cermet, it is vaporized at high temperature; $\mathrm{UO}_{2}$ has a vapor pressure of $348.6 \mathrm{~Pa}$ at $2768 \mathrm{~K} .^{18}$ Vaporization can also occur if $\mathrm{UO}_{2}$ is exposed to cracks that connect to the surface. For $\mathrm{UO}_{2}$ in the bulk of the cermet, more complex mechanisms take place. One such mechanism results from the reduction to hypostoichiometric $\mathrm{UO}_{2-x}$ at temperatures above $1500 \mathrm{~K}$, releasing oxygen; free $\mathrm{U}$ forms once the temperature cools, i.e.,

$$
\begin{gathered}
U O_{2} \rightarrow U O_{2-x}+x O(>1500 \mathrm{~K}), \\
2 U O_{2-x} \rightarrow(2-x) U O_{2}+x U(\text { After cooling }) .
\end{gathered}
$$

The free $\mathrm{U}$ and $\mathrm{O}$ both migrate along metal matrix grain boundaries until they find a free surface and are vaporized. They can recombine to form $\mathrm{UO}_{2}$, and the strain associated with this formation can form cracks along the grain boundaries. The cracks can act as fast migration paths for $\mathrm{U}$ and $\mathrm{UO}_{2}$ to free surfaces, where they are vaporized. In the presence of hydrogen, this reaction alters somewhat:

$$
\begin{gathered}
\mathrm{UO}_{2}+x \mathrm{H}_{2} \rightarrow \mathrm{UO}_{2-x}+x \mathrm{H}_{2} \mathrm{O}(>1500 \mathrm{~K}), \\
\left.2 \mathrm{UO}_{2-x} \rightarrow(2-x) \mathrm{UO}_{2}+x U \text { (After cooling }\right) .
\end{gathered}
$$


The free $\mathrm{U}$ again migrates along metal matrix grain boundaries, but it can combine with hydrogen to form $\mathrm{UH}_{3}$, which also strains the material to form cracks that act as fast diffusion paths. These same mechanisms were observed irrespective of the refractory metal used for the matrix, whether pure $\mathrm{W}$ and Mo or various alloys of W, Mo, and Re.

The impacts of various experimental conditions on fuel loss were also investigated. Exposure of the cermet to hot hydrogen resulted in more fuel loss than temperature tests in a vacuum or exposed to helium (He). It was also found that fuel loss accelerated with increasing gas pressure and gas flow rate. In addition, fuel loss accelerated with increasing temperature and time at high temperature in experiments involving thermal cycling. Thermal cycling accelerated fuel loss, though the heating and cooling rates did not have a large impact.

Various strategies were also identified to reduce fuel loss in $\mathrm{UO}_{2}$ cermets. One successful strategy was the addition of oxides that form solid solutions with $\mathrm{UO}_{2}$. They acted as oxygen stabilizers and reduced fuel loss. Another successful strategy was coating the $\mathrm{UO}_{2}$ particles in $\mathrm{W}$ before fabrication of the cermet. The coatings contained the fuel better and resulted in less fuel loss. Adding thorium oxide
$\left(\mathrm{ThO}_{2}\right)$ and yttrium oxide $\left(\mathrm{Y}_{2} \mathrm{O}_{3}\right)$ to the metal matrix was also shown to reduce fuel loss. It was hypothesized that this is because the additive reduced grain growth, which created more grain boundary area and a longer diffusion path between free surfaces and fuel particles. Using smaller metal particles when fabricating the cermet also reduced fuel loss. Finally, metal cladding around the cermet (e.g., in the coolant channels of a fuel element) also resulted in a significant reduction in fuel loss.

Recent tests on UN cermets carried out at NASA MSFC have illustrated that similar mechanisms may occur to those that cause fuel loss in $\mathrm{UO}_{2}$ cermets. Figure 3 shows scanning electron microscopy (SEM) and energy-dispersive spectroscopy (EDS) characterization on a cermet comprising 60 vol.\% UN fuel in a metal matrix created from a mixture of Mo and $\mathrm{W}$ powders. It was radiatively heated and exposed to hydrogen; the temperature was ramped at $100 \mathrm{~K} / \mathrm{min}$ to $2250 \mathrm{~K}$ and then held for $20 \mathrm{~min}$ (the fuel element prior to testing is shown in Fig. 2). Figure 3a shows an SEM image with many cracks through the UN particles. Thus, it appears that cracking occurs in UN cermets, just as it does in $\mathrm{UO}_{2}$ cermets. Figure $3 \mathrm{~b}$ shows an image of cermet fuel adjacent to Mo cladding; EDS data for the same region (Fig. 3c) shows that $U$ was

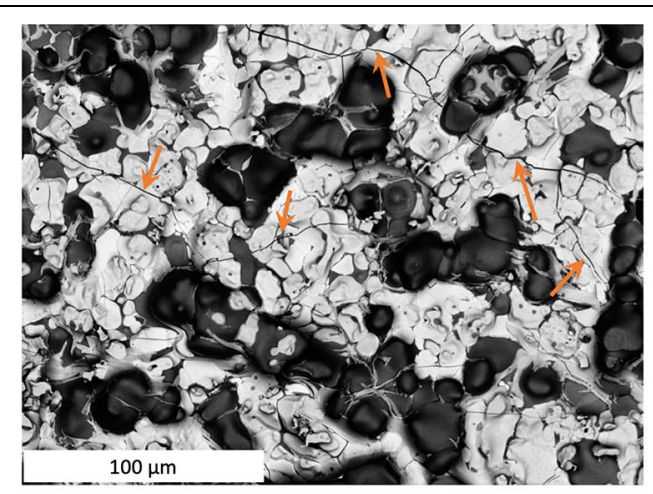

(a)

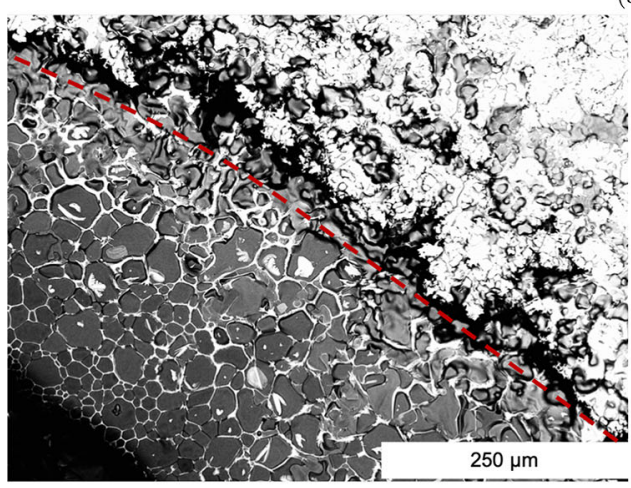

(b)

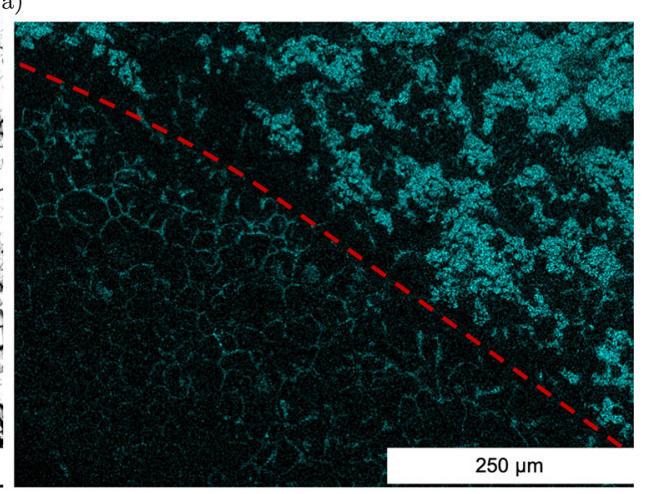

(c)

Fig. 3. Microstructure characterization of a W/Mo-UN cermet ( 60 vol.\% UN) that was radiatively heated to $2250 \mathrm{~K}$ and held for $20 \mathrm{~min}$ : (a) SEM image of UN particles showing cracking (with some cracks marked with orange arrows), where the fuel is light gray and the matrix is dark gray; (b) SEM image of a section of cermet adjacent to the Mo cladding; (c) $U$ distribution in image (b) from EDS showing $U$ along the metal cladding grain boundaries, where $U$ is shaded teal and other elements are black. In (b) and (c), the interface between the fuel and cladding is marked with a red dashed line. The cladding is below and to the left of the line. In the fuel region, the fuel is the lighter gray and the matrix is the darker gray. The heating and characterization were recently carried out at NASA MSFC. 


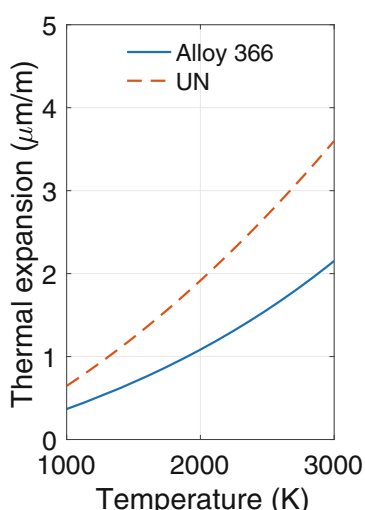

(a)

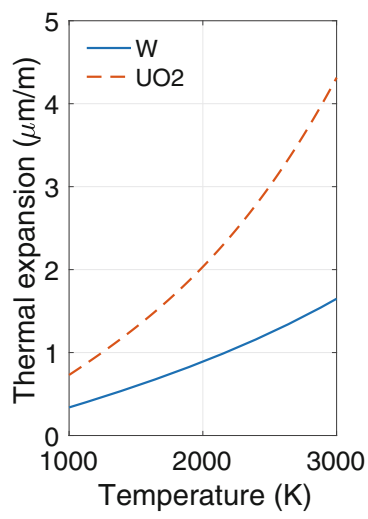

(b)
Fig. 4. Thermal expansion in fuel and metal matrix materials, comparing (a) Alloy 366 and $\mathrm{UN}$ and (b) $\mathrm{W}$ and $\mathrm{UO}_{2}$. The expansion varies between Alloy 366 and UN, but less than the amount it varies in $\mathrm{W}$ and $\mathrm{UO}_{2}$. The $\mathrm{UO}_{2}$ thermal expansion comes from Martin, ${ }^{20}$ while the W, Alloy 366 , and UN thermal expansions come from the NASA NTP Materials Data Property Book ${ }^{19}$.

transported along the metal cladding grain boundaries. This indicates that some dissociation of $U$ likely occurs, freeing $U$ to transport into the metal matrix, similar to what occurs in $\mathrm{UO}_{2}$ cermets.

To better understand the crack formation that was evident in the tested UN cermet sample (Fig. 3a), we look at the thermal expansion coefficients for UN and Alloy 366 (Mo and W alloy with 30 wt.\% W). We take the values from the NASA NTP Materials Data Property Book. ${ }^{19}$ As shown in Fig. $4 \mathrm{a}$, the thermal expansion of UN is about $60 \%$ larger than that of Alloy 366 at typical operating temperatures of NTP fuel. Thus, the UN fuel particles will change size more as the temperature changes than the metal matrix, inducing thermal strains and causing cracking. However, as shown in Fig. $4 \mathrm{~b}$, the difference between the thermal expansion in UN and Alloy 366 at high temperature is smaller than the difference in $\mathrm{UO}_{2}$ and $\mathrm{W}$. Whether this smaller difference would directly translate to less cracking needs to be investigated.

To attempt to understand the U concentrations on the cladding grain boundaries shown in Fig. 3c, we need to consider the stability of UN at high temperature. Various researchers have established that UN experiences a decomposition reaction at high temperature and low $\mathrm{N}$ partial pressure, producing liquid $\mathrm{U}$ and $\mathrm{N}_{2}$ gas. ${ }^{21-25}$ At lower temperature and higher $\mathrm{N}$ partial pressure, $\mathrm{UN}$ forms the $\mathrm{U}_{2} \mathrm{~N}_{3}$ phase. $^{21,22}$ Early $\mathrm{N}$ release starts at $1600 \mathrm{~K}$, and precipitation of liquid $\mathrm{U}$ begins at $2120 \mathrm{~K} .^{24}$ This decomposition likely could cause release of $U$ from the fuel kernel and diffusion into the metal matrix grain boundaries, which will contribute to fuel loss. Thus, the reactions that will take place in a UN cermet, similar to the $\mathrm{UO}_{2}$ reactions from Eqs. 1 and 2 , are

$$
2 U N(s) \rightarrow 2 U(l)+N_{2}(g)(>2120 K),
$$

$$
2 U(s)+N_{2}(g) \rightarrow 2 U N(s) \text { (After cooling). }
$$

The liquid $\mathrm{U}$ and gaseous $\mathrm{N}_{2}$ that form in the fuel can diffuse into the metal matrix along grain boundaries. When the temperature lowers, it is possible that they would recombine and form UN on the grain boundaries, causing strain. In the presence of hydrogen, Eq. 6 is unchanged but Eq. 5 becomes

$$
2 U N+3 H_{2} \rightarrow 2 U+2 \mathrm{NH}_{3}(>2120 \mathrm{~K}),
$$

When the free $U$ on the metal matrix grain boundaries comes into contact with $\mathrm{H}$, it could also form $\mathrm{UH}_{3}$, causing strain and cracking.

Having established that fuel loss is likely to occur in UN cermets via similar mechanisms to those that occur with $\mathrm{UO}_{2}$, it is also worth considering whether the successful strategies for reducing fuel loss in $\mathrm{UO}_{2}$ cermets might be applicable to UN cermets. While oxide additives to $\mathrm{UO}_{2}$ effectively reduced fuel loss, the same additives would likely not have a beneficial effect in UN. Raising the $\mathrm{N}$ partial pressure can decrease the dissociation of UN. The addition of zirconium ( $\mathrm{Zr}$ ) nitride to $\mathrm{UN}$ has been shown to decrease the mass loss by as much as $50 \%$, with 3 wt.\% to 5 wt.\% $\mathrm{Zr}$ giving the best protection. ${ }^{26,27}$ Other dopants, such as chromium, nickel, aluminum, and cerium, have been investigated for improving the stability of UN when exposed to water (with only $\mathrm{Cr}$ being shown to be significantly beneficial), ${ }^{28-30}$ but their impact on the high-temperature dissociation of UN was not investigated. It may be possible to identify other additives that reduce UN decomposition. Coating UN fuel particles will likely reduce fuel loss, as will cladding the cermet fuel. Methods to reduce the grain size of the metal matrix, whether additives to reduce grain growth or small particles to reduce the initial grain size, will also likely reduce fuel loss in UN cermets.

These preliminary analyses show that strain will occur due to the different thermal expansion in the fuel and metal matrix, but it may be less than what is experienced in $\mathrm{UO}_{2}$ cermets. Uranium release has the potential to occur due to UN decomposition at high temperature and could result in fuel loss. However, more detail about the potential behavior in UN cermets can be obtained using modeling and simulation. In the following sections, we employ simple simulations to investigate cracking in UN cermets due to thermal strain (Sect. 3) and $U$ decomposition and diffusion (Sect. 4).

\section{CERMET CRACKING}

As discussed in the previous section, microcracking has a large impact on fuel loss, since it provides fast paths for $U$ atoms that are released from the fuel to transport to free surfaces and be vaporized. Microcracking occurs in the cermet as a result of 
thermal strains. As the temperature changes, the UN particles and the metal matrix will change volume by different amounts, inducing stress that causes fracture. To provide a preliminary estimate of the fracture that may occur in an Alloy 366-UN cermet, we have developed a model that predicts discrete crack formation in a cermet microstructure. We first summarize the model, then use it to investigate microcracking during thermal cycling. Fracture could also occur due to strain caused by the formation of $\mathrm{UN}$ and $\mathrm{UH}_{3}$ along matrix grain boundaries; however, we only consider thermal strains in this work.

\section{Fracture Model}

To model the nucleation and propagation of cracks in a cermet caused by thermal strains, we employ the phase-field fracture method. The phasefield fracture method has emerged as a popular means of modeling discrete crack formation due to its ability to accurately represent crack initiation, propagation, branching, and merging in both two dimensions (2D) and three dimensions (3D). ${ }^{31}$ In this method, a continuous variable field $d$ is used to represent cracks, and it is evolved to minimize the total strain energy of the system. $d=0$ in intact material, $d=1$ in cracked material, and $d$ smoothly transitions between these values through the crack surface. Due to the continuous nature of the crack field, cracks have a finite width and the need to track the crack surface is eliminated.

To approximate the fracture in cermet fuel due to thermal strain, we employ the phase-field fracture model from Zhang et al. ${ }^{32}$ that has been applied to model fracture due to thermal strain in $\alpha$-U polycrystals. $^{33}$ There is insufficient information in literature to accurately model the single-crystal mechanical behavior of UN or Alloy 366. Therefore, we approximate the single-crystal mechanical behavior with macroscale models, assuming elastic isotropy, isotropic thermal expansion, and J2 plastic deformation (where the transition from elastic to plastic deformation is described with a yield stress). We also assume that the fracture energy release rate $G_{\mathrm{c}}$ is isotropic within grains of both the fuel and matrix material and that the energy stored by plastic deformation does not contribute to fracture. As further information becomes available in the future with regards to the mechanical behavior of single-crystal UN and Alloy 366, the mechanical behavior could be modeled more accurately.

The total free energy of the material consists of strain energy and fracture energy, according to

$$
F=\int_{\Omega}\left(g(d) \psi^{+}+\psi^{-}+\frac{G_{\mathrm{c}} d^{2}}{2 l}+\frac{g_{\mathrm{c}} l}{2} \nabla \cdot \nabla d\right) d V
$$

where $l$ is a parameter that defines the width of the crack, and $g(d)=\left((1-d)^{2}(1-k)+k\right)$ is a degradation function. $k=1 \times 10^{-6}$ is a small number included to improve numerical convergence; the value was determined using a convergence study to determine the best balance between accuracy and numerical convergence. The strain energy density is divided into the portion that contributes to fracture $\psi^{+}$and the portion that does not $\psi^{-}$.

The undamaged stress $\sigma_{0}$ at a given material point is calculated according to

$$
\boldsymbol{\sigma}_{0}=\mathcal{C}\left(\varepsilon_{\mathrm{el}}-\alpha\left(T-T_{0}\right)\right) \mathbf{I},
$$

where $\mathcal{C}$ is the isotropic elasticity tensor, $\varepsilon_{\mathrm{el}}$ is the elastic strain calculated using the radial return method, $\mathbf{I}$ is the second-order identity tensor, $\alpha$ is the average thermal expansion coefficient, $T$ is the temperature, and $T_{0}$ is a reference temperature with no thermal strain. The plastic deformation is governed by the yield stress $\sigma_{y}$ and is assumed to be perfectly plastic. The strain $\varepsilon=\left(\nabla \mathbf{u}+\nabla \mathbf{u}^{T}\right) / 2$ is decomposed into its elastic and plastic parts, i.e. $\varepsilon=\varepsilon_{\mathrm{el}}+\varepsilon_{\mathrm{pl}}$.

To decompose the strain energy density into $\psi^{+}$ and $\psi^{-}$, we first apply a spectral decomposition to the undamaged stress $\boldsymbol{\sigma}_{0}=\sum_{a} \sigma_{a} \mathbf{n}_{\mathbf{a}} \otimes \mathbf{n}_{a}$, where $\sigma_{a}$ is the $a$ th eigenvalue corresponding the the eigenvector $\mathbf{n}_{a}$. The spectral decomposition can be written in tensor form as

$$
\sigma_{0}=\boldsymbol{Q} \Lambda \boldsymbol{Q}^{\mathrm{T}},
$$

where $\Lambda=\operatorname{diag}\left(\sigma_{1}, \sigma_{2}, \sigma_{3},\right)$ is a diagonal matrix containing the three eigenvalues and $\boldsymbol{Q}=$ $\left[\mathbf{n}_{1}, \mathbf{n}_{2}, \mathbf{n}_{3}\right]$ is a matrix containing the three corresponding eigenvectors. Positive eigenvalues of the stress (tensile stress) contribute to fracture while negative eigenvalues (compressive stress) do not, such that

$$
\begin{gathered}
\boldsymbol{\sigma}^{+}=\mathbf{Q} \Lambda^{+} \mathbf{Q}^{\mathrm{T}}, \\
\boldsymbol{\sigma}^{-}=\mathbf{Q} \Lambda^{-} \mathbf{Q}^{\mathrm{T}},
\end{gathered}
$$

where $\quad \Lambda^{ \pm}=\operatorname{diag}\left(\left\langle\lambda_{1}\right\rangle_{ \pm},\left\langle\lambda_{2}\right\rangle_{ \pm},\left\langle\lambda_{3}\right\rangle_{ \pm}\right) \quad$ with $\langle a\rangle_{ \pm}=(a \pm|a|) / 2$. Then, $\psi^{+}$and $\psi^{-}$are determined according to

$$
\psi^{ \pm}=\frac{1}{2} \sigma^{ \pm}: \varepsilon_{\mathrm{el}}
$$

Crack formation and propagation is defined by the evolution of the crack field $d$, which is driven by dissipation of the free energy of the system. The evolution is assumed to be quasistatic, such that

$$
\frac{\partial g(d)}{\partial d} \mathcal{H}+\frac{G_{\mathrm{c}} d}{l}-G_{\mathrm{c}} l \Delta d=0 \text {. }
$$

To avoid crack healing, we alter the bulk energy by introducing the history variable

$$
\mathcal{H}=\max \psi^{+} \text {for } t=\left[0, t_{\mathrm{c}}\right],
$$


where $t_{\mathrm{c}}$ is the current time. ${ }^{34}$

At a given material point with a given value of the crack field $d$, the local stress is determined according to

$$
\boldsymbol{\sigma}(d)=g(d) \boldsymbol{\sigma}^{+}+\boldsymbol{\sigma}^{-} .
$$

The displacement vector field $\mathbf{u}$ is determined by solving the stress divergence equation,

$$
\nabla \cdot \boldsymbol{\sigma}=0
$$

with appropriate boundary conditions to represent the mechanical loading of the material. As mentioned above, the elastic portion of the strain is determined using the radial return method, since the constitutive behavior of the fuel is determined using J2 plasticity.

\section{Material Properties and Model Parameters}

The phase-field fracture model summarized in the previous section uses various material properties, including the Young's modulus, shear modulus, yield stress, and fracture stress, and also considers the thermal expansion of the matrix and fuel regions. Modeling the behavior in Alloy 366-UN cermet fuel thus requires these properties for both materials. The model also includes the length parameter $l$. In this section, we describe the values we use for the material properties and for $l$.

The majority of the material properties used in this study come from data in the NTP handbook. ${ }^{19}$ Temperature-dependent fits for each property are taken from the handbook, when available. The Young's and shear moduli for Alloy 366 are not available in the handbook, so we obtain them using a weighted sum of the properties for Mo and W from the handbook, weighted by 0.7 for Mo and 0.3 for W. Their Young's and shear moduli are fit using a polynomial function:

$$
f_{\text {poly }}=\sum_{i=0}^{N} C_{i}\left(\frac{T}{1000}\right)^{i}
$$

where $T$ is the temperature in Kelvin, $N=3$ for Mo, and $N=2$ for W. The UN Young's and shear moduli follow a power law,

$$
f_{\text {power }}=C_{0}\left(1-\phi_{\mathrm{f}}\right)^{n}\left[C_{1}-C_{2}(T-273)\right],
$$

where $\phi$ is the porosity of the UN fuel, which is assumed to be 0.05 . The thermal expansion coefficient for Alloy 366 is

$$
\alpha_{366}=\frac{\sum_{i=0}^{3} C_{i}\left(\frac{T}{1000}\right)^{i}}{C_{4}+\left(\frac{T}{1000}\right)^{n}},
$$

and for UN is

$$
\alpha_{U N}=\frac{\sum_{i=0}^{2} C_{i}\left(\frac{T}{1000}\right)^{i}}{1+C_{3}\left(\frac{T}{1000}\right)} .
$$

For both materials, we use a reference temperature $T_{0}=1535.5 \mathrm{~K}$, which is representative of typical cermet fabrication temperatures. The property, fitting equation, and fitting coefficients for the material properties can be found in Table I.

While there are data for the yield stress of Alloy 366 in the NTP handbook, there is no value for its fracture stress. Therefore, for this preliminary study, we somewhat arbitrarily selected values for $\mathrm{W}^{35}$ for the yield and fracture stresses of the matrix metal. In future work, it will be important to obtain accurate mechanical properties for Alloy 366 to obtain more quantitative results. There are no data available regarding the yield or fracture stresses of $\mathrm{UN}$, though there is some evidence that it is brittle. ${ }^{36}$ Therefore, we assume that the yield and fracture stresses for UN are similar to those for $\mathrm{UO}_{2}$, using the data from Evans and Davidge. ${ }^{37}$ Both yield stresses are assumed to follow an exponential function,

$$
\sigma_{y}=C_{0} \exp \left(C_{1} T\right) ;
$$

the parameter values are fit to their respective data

\begin{tabular}{|c|c|c|c|c|c|c|c|c|}
\hline Property & Equation & $C_{0}$ & $C_{1}$ & $C_{2}$ & $C_{3}$ & $C_{4}$ & $n$ & Ref. \\
\hline$E_{\mathrm{Mo}}$ & Eq. 18 & 329.7 & -41 & 2.065 & -3.517 & - & - & [19] \\
\hline$E_{\mathrm{W}}$ & Eq. 18 & 404.9 & -13.97 & -13.01 & 0 & - & - & [19] \\
\hline$E_{\mathrm{UN}}$ & Eq. 19 & 263.547 & 1.003 & $1.148 \times 10^{-4}$ & - & - & 3.071 & [19] \\
\hline$G_{\mathrm{Mo}}$ & Eq. 18 & 129.5 & -19 & 0.8578 & -1.286 & - & - & [19] \\
\hline$G_{\mathrm{W}}$ & Eq. 18 & 164 & -12.77 & -3.28 & 0 & - & - & [19] \\
\hline$G_{\mathrm{UN}}$ & Eq. 19 & 103.999 & 1.003 & $1.148 \times 10^{-4}$ & - & - & 2.893 & [19] \\
\hline$\alpha_{366}$ & Eq. 20 & 0.2218 & 3.986 & 1.168 & 0.2319 & 0.08128 & 1.158 & [19] \\
\hline$\alpha_{\mathrm{UN}}$ & Eq. 21 & 4.383 & 50.92 & 6.584 & 5.965 & - & - & [19] \\
\hline$\sigma_{y}^{\text {matrix }}$ & Eq. 22 & 6.884 & -0.004349 & - & - & - & - & W [35] \\
\hline$\sigma_{y}^{\text {fuel }}$ & Eq. 22 & 1.722 & -0.001516 & - & - & - & - & $\mathrm{UO}_{2}$ [37] \\
\hline
\end{tabular}
and are presented in Table I. The fracture stresses are assumed to be constant with temperature, to simplify the simulations. We determine the values of the fracture stress using the measured ductile to

Table I. Parameters used to define the material properties used in the phase-field fracture model for Alloy 366 and UN 
brittle transition temperatures (DBTT); we set the fracture stress equal to the yield stress at the DBTT. The fracture stress for the matrix $\sigma_{\mathrm{f}}^{\text {matrix }}=0.19 \mathrm{GPa}$ and for the fuel $\sigma_{\mathrm{f}}^{\text {fuel }}=0.12 \mathrm{GPa}$. For the fuel, this fracture stress is very similar to that from the data; for the matrix, it is lower than that from the data. However, fracture in the cermet is still preferred in the fuel, so it does not significantly impact the results of our simulations. The data and fits for the matrix and fuel yield and fractures stresses are illustrated in Fig. 5. Uniaxial tension simulations were conducted for the fuel and the matrix, and the energy release rates $\left(G_{\mathrm{c}}\right)$ were adjusted iteratively until each material cracked at the correct fracture stress. The resultant values are $G_{\mathrm{c}}^{\text {matrix }}=0.22 \mathrm{~Pa} \mathrm{~m}$ and $G_{\mathrm{c}}^{\text {fuel }}=0.16 \mathrm{~Pa} \mathrm{~m}$. We assume that interface and grain boundary fracture is preferred and therefore set the energy release rate in the matrix grains to $10 G_{\mathrm{c}}^{\text {matrix }}$, in the matrix grain boundaries to $G_{\mathrm{c}}^{\text {matrix }}$, in the fuel grains to $10 G_{\mathrm{c}}^{\text {fuel }}$, and in the fuel grain boundaries to $G_{\mathrm{c}}^{\text {fuel }}$. At the fuel-matrix interface, the energy release rate transitions smoothly between $G_{\mathrm{c}}^{\text {fuel }}$ and $G_{\mathrm{c}}^{\text {matrix }}$.

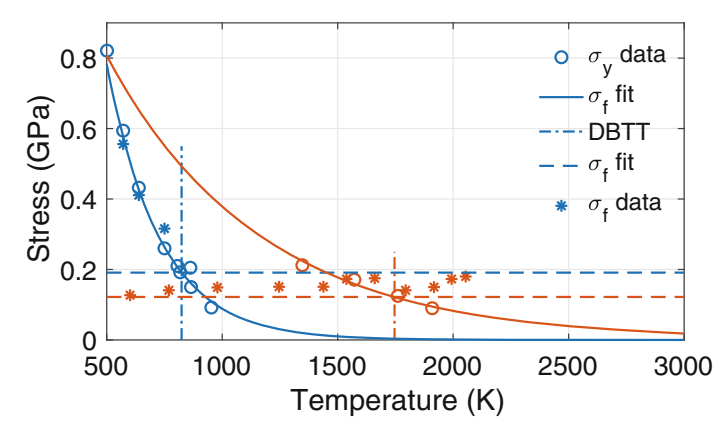

Fig. 5. Values used for the yield and fracture stresses in the phasefield fracture simulations. The blue values are for the matrix, and the orange values for the fuel. The yield stress $\sigma_{y}$ curves are fit to the data. The yield stresses at the measured DBTTs are used for the fracture stresses $\sigma_{\mathrm{f}}$. The experimental data for the matrix (approximated as W) are taken from Raffo, ${ }^{35}$ while those for the fuel (approximated as $\cup_{2}$ ) are taken from Evans and Davidge. ${ }^{37}$
The phase-field fracture model was implemented using the finite element method with the Multiphysics Object-Oriented Simulation Environment (MOOSE), ${ }^{38}$ as was done with the original model. ${ }^{1}$ The J2 plasticity model in MOOSE was used to describe the constitutive behavior. Implicit time integration was used in the model.

We selected a value for $l$ using a convergence study to determine a value that did not significantly impact the results. Our study showed that a length parameter $l=0.4 \mu \mathrm{m}$ was sufficient, and we use an element size of $0.25 \mu \mathrm{m}$ to ensure that there are sufficient elements to resolve the crack. ${ }^{39}$ We use zero-flux boundary conditions on all sides for the crack field $d$. We set the $x$ - and $y$-displacements to zero at a node at the center of the domain.

\section{Cermet Fracture Simulation Results}

Having summarized the phase-field fracture model for the cermet fuel, we now apply it to simple cermet microstructures to demonstrate its capabilities. We use it to estimate likely crack locations in a Alloy 366-UN cermet fuel. We model fracture in a small section of an idealized cermet structure in $2 \mathrm{D}$ in which the temperature is repeatedly increased and decreased. The microstructure of the $64 \times 64$ $\mu \mathrm{m}$ cermet section is shown in Fig. 6a. It contains one full circular UN particle with a radius of $20 \mu \mathrm{m}$ and one-quarter of a circular UN particle on each of the four corners. The UN particles are embedded in a matrix of Alloy 366. There is a distinct interface region between the fuel and matrix and a simple grain structure that divides the simulation horizontally and vertically through middle. The interface and grain boundary regions have thicknesses of 2.5 $\mu \mathrm{m}$. It is represented with a finite element mesh of $256 \times 256$ elements, with an element size of 0.25 $\mu \mathrm{m}$. The impact of more realistic particle shapes will be investigated in future work.

The temperature profile applied to the sample is shown in Fig. 6b. The material begins at $1535.5 \mathrm{~K}$ and is then cooled linearly to $298 \mathrm{~K}$ over $0.5 \mathrm{~min}$. The temperature is then cycled between $298 \mathrm{~K}$ and $2773 \mathrm{~K}$ five times, with each full cycle taking $2 \mathrm{~min}$.

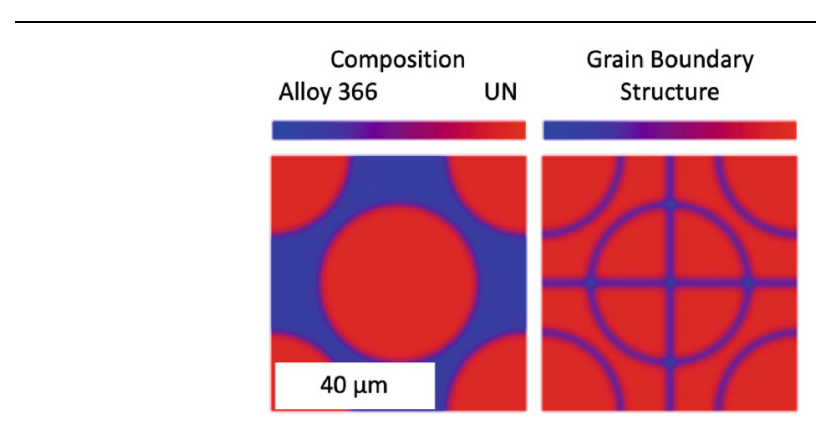

(a)

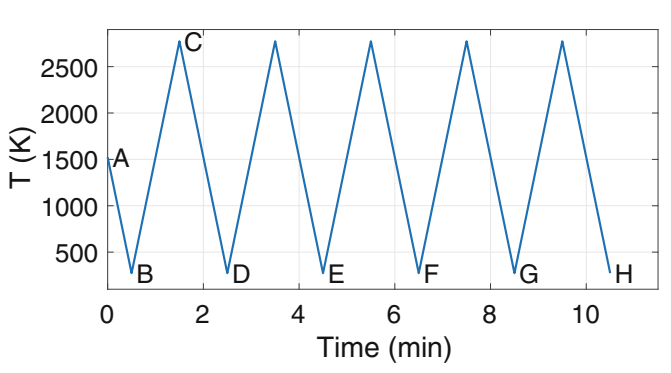

(b)

Fig. 6. Problem setup for the cermet fracture simulations: (a) The 2D simulation domain; the fuel particles are shown in the image on the left and the interfaces and grain boundaries are shown on the right. The grains have a higher $G_{c}$ value than the interfaces and grain boundaries, making them less likely to crack. (b) The temperature profile applied to the material. The letters correspond to the images in Fig. 7. 


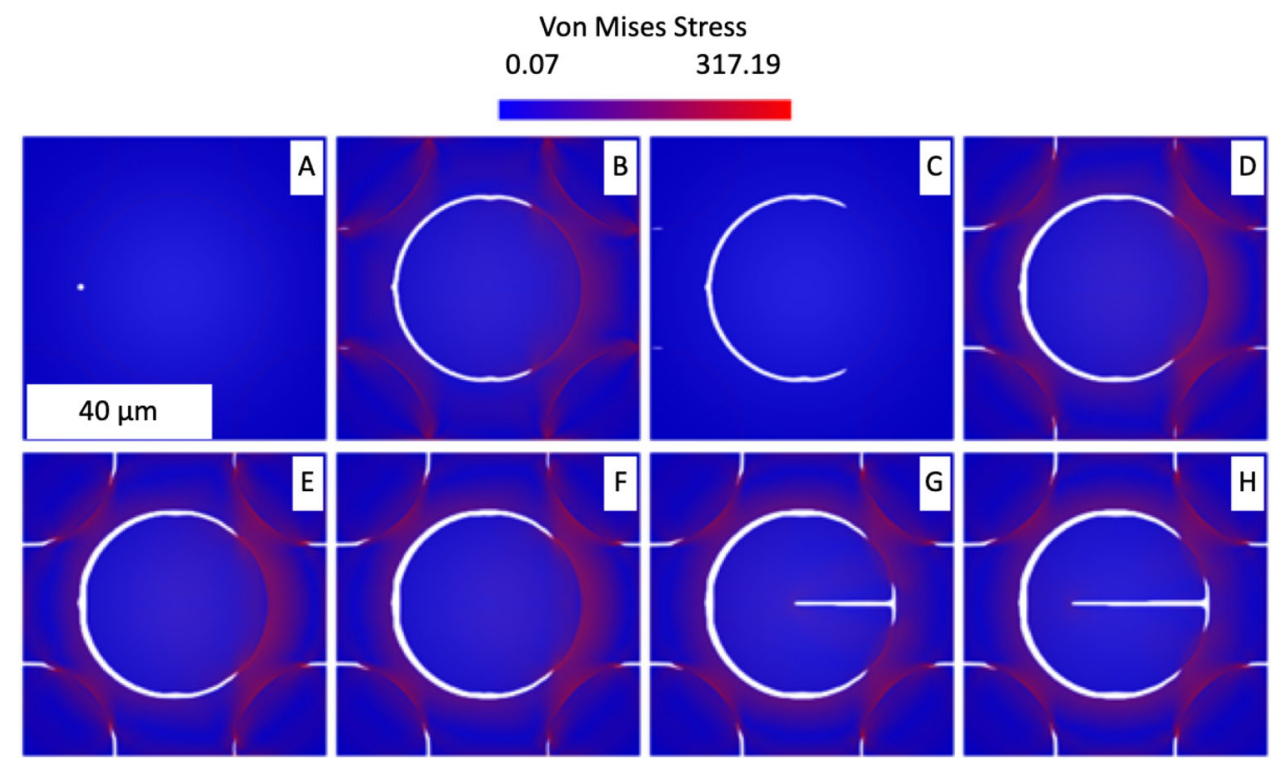

Fig. 7. Phase-field fracture simulation results for the 2D Alloy 366-UN domain shown in Fig. 6 a due to the applied temperature profile shown in Fig. $6 \mathrm{~b}$. Images are shaded by von Mises stress (units of MPa), and cracks are shown in white. Each image shows the simulation domain at a specific time during the simulation. The times and temperatures for each image are marked in Fig. $6 \mathrm{~b}$. Specifically, A-H correspond to 0 min, 0.5 $\mathrm{min}, 1.5 \mathrm{~min}, 2.5 \mathrm{~min}, 4.5 \mathrm{~min}, 6.5 \mathrm{~min}, 8.5 \mathrm{~min}$, and $10.5 \mathrm{~min}$, respectively.

The thermal strains induced in the materials during these temperature cycles result in fracture. Note that this temperature profile is used to demonstrate the capabilities of the model and is not representative of temperatures that would be experienced during actual propulsion cycles. The ramp rates would likely be higher, and it would likely be held at high temperature for several minutes.

The results from the phase-field fracture simulations are shown in Fig. 7. The simulation begins at the reference temperature $T_{0}$ so there are no initial stresses. We initialize a small crack at the interface with the matrix on the left of the center UN particle (Fig. 7A). As the material cools, the UN particles contract more than the Alloy 366, causing tensile stress and fracture around roughly two-thirds of the interface of the center particle (Fig. 7B). As the material heats up again, the tensile stresses relax, and eventually the material goes into compression because the UN particles expand more than the Alloy 366 (Fig. 7C). Once again, as the material cools, the material goes into tension, and cracks begin to form at the interfaces of the other four particles (Fig. 7D). During each subsequent cooling cycle, additional crack propagation occurs. During the fourth cooling cycle, cracks have formed along the horizontal grain boundary in the center UN particle (Fig. 7G). Little additional cracking occurs during the final cooling cycle (Fig. 7H).

Our phase-field fracture model results illustrate several general trends that will potentially impact fuel loss in UN cermet fuel. Due to our assumption that the material is less likely to fracture in grains than along grain boundaries and interfaces, no cracks form within fuel or metal grains. The results indicate that the stress induced by the thermal expansion mismatch between UN and Alloy 366 is likely to result in cracking. The cracking is most likely to occur during cooling rather than during heating. Our results also show that the interfaces between the fuel particles and the metal matrix will likely fracture first and that the fuel particle grain boundaries are likely to crack in later cycles. No cracks form in the metal matrix. The SEM image shown in Fig. 3a also shows no cracks in the metal matrix.

\section{FUEL LOSS}

Having investigated the fracture behavior using phase-field fracture simulations, we now consider fuel loss. As mentioned in Sect. 2, potential mechanisms for fuel loss in UN cermets include direct vaporization of $U$ atoms at free surfaces and dissociation of UN to form liquid U (Eq. (5)) that can then diffuse through the matrix until reaching a free surface. To better understand this potential fuel loss mechanism, we first develop a mesoscale model of fuel loss in a cermet microstructure and then apply it to model fuel loss.

\section{Fuel Loss Model}

Our mesoscale model of fuel loss represents the fuel microstructure using static fields. There are four regions of material represented in the model: UN fuel particles represented by $\eta_{\mathrm{f}}$, Alloy 366 
matrix represented by $\eta_{\mathrm{m}}$, grain boundary represented by $\eta_{\mathrm{b}}$, and cracks represented by $\eta_{\mathrm{c}} \cdot \eta_{\mathrm{f}}, \eta_{\mathrm{m}}$, and $\eta_{\mathrm{c}}$ are equal to 1 within a region they represent, equal to 0 in the other regions, and smoothly transition between 0 and 1 at interfaces between regions. $\eta_{\mathrm{b}}=1$ within a grain, and it smoothly transitions to $\eta_{b}=0.5$ in the center of the grain boundary. These variable fields are used in switching functions that interpolate parameter values across the interfaces; the switching functions are defined according to

$$
h\left(\eta_{i}\right)=\frac{1}{2}\left(1+\tanh \left(4 \pi A\left(\eta_{i}-B\right)\right)\right),
$$

where $A$ and $B$ are defined in Table II for the different regions of the material. The switching function for the Alloy 366 matrix $h_{\mathrm{m}}=1-h_{\mathrm{f}}$. $h_{\mathrm{f}}$ and $h_{\mathrm{m}}$ interpolate between fuel and matrix regions, $h_{\mathrm{b}}$ interpolates between grain and grain boundary regions, and $h_{\mathrm{c}}$ interpolates between cracked and uncracked regions.

The fuel loss model predicts the transport of free uranium through the cermet microstructure, where the concentration of free uranium in the material is defined by the molar fraction $x_{\mathrm{U}}$. The evolution of $x_{\mathrm{U}}$ is defined by the diffusion equation

$$
\frac{\partial x_{\mathrm{U}}}{\partial t}=\nabla \cdot D_{\mathrm{U}} \nabla x_{\mathrm{U}}+R_{\mathrm{U}}
$$

where $t$ is the time, $D_{\mathrm{U}}$ is the diffusion coefficient, and $R_{\mathrm{U}}$ is the rate at which free uranium is generated by thermal dissociation in the UN fuel particles. The generation rate is defined as

Table II. Values for $A$ and $B$ in Eq. (23)

\begin{tabular}{lcccc}
\hline Region & Function & & $\boldsymbol{A}$ & $\boldsymbol{B}$ \\
\cline { 5 - 5 } Fuel & $h_{\mathrm{f}}$ & & 1 & 0.5 \\
Crack & $h_{\mathrm{c}}$ & 1 & 0.5 \\
Grain boundary & $h_{\mathrm{b}}$ & -1 & 0.7 \\
\hline
\end{tabular}

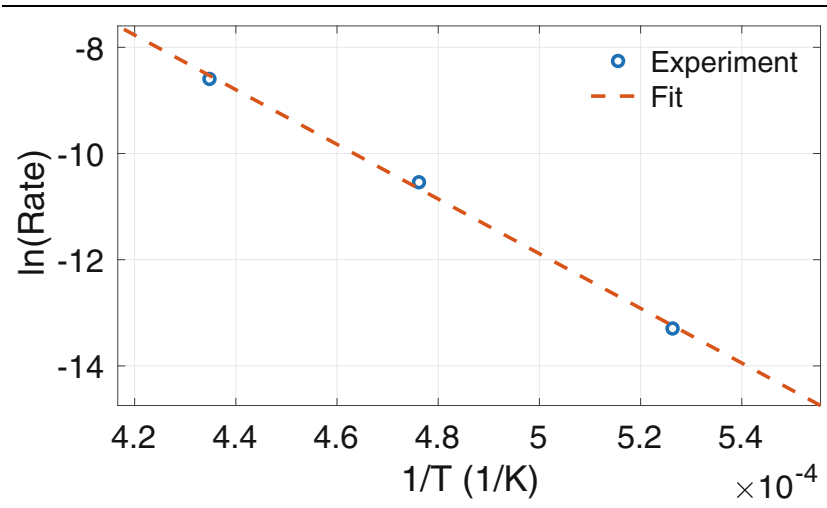

Fig. 8. The creation of an exponential fit of the decomposition rate of UN with temperature based on experimental data. ${ }^{23}$

$$
R_{\mathrm{U}}=h_{\mathrm{f}}\left(\eta_{\mathrm{f}}\right) A \exp ^{\frac{-B}{R T}},
$$

where $A=2.617 \times 10^{5}, B=5.476 \times 10^{5}, R$ is the ideal gas constant in $\frac{J}{m o l K}$, and $T$ is the temperature. $A$ and $B$ are obtained from an exponential fit to experimental data, ${ }^{23}$ as shown in Fig. 8. The switching function $h_{\mathrm{f}}$ is used to set the production of $U$ to zero except within the fuel particles. The recombination of $\mathrm{U}$ and $\mathrm{N}$ defined by Eq. (6) and the behavior of free $\mathrm{N}$ atoms are not considered in this work.

The diffusion coefficient for free uranium $D_{\mathrm{U}}$ has different values in the UN fuel and the Alloy 366 matrix. In addition, it is larger along grain boundaries than in grains. It is the largest in cracks. Unfortunately, data are not available to define the diffusion coefficient of $U$ atoms in these materials. In addition, the diffusion coefficient will also be impacted by irradiation, though for other fuels this radiation effect is most significant at lower temperature. ${ }^{40,41}$

However, we can still use the fuel loss model to explore the impact of various aspects of the cermet microstructure. Rather than use nondimensional values for the diffusion coefficients, we instead approximate the diffusion coefficient of $U$ along fuel grain boundaries using a value for $\mathrm{U}$ in $\mathrm{UO}_{2}{ }^{42}$ and the diffusion coefficient of $U$ along matrix grain boundaries using a value for $\mathrm{U}$ in $\mathrm{W} .{ }^{43} \mathrm{We}$ also neglect radiation effects. Each of these values is determined using an Arrhenius expression

$$
D=D_{0} \exp ^{\frac{-Q}{R T}}
$$

where the $D_{0}$ and $Q$ used to calculate the diffusion coefficient along fuel grain boundaries $D_{\mathrm{fb}}$ and along matrix grain boundaries $D_{\mathrm{mb}}$ are given in Table III. The diffusion of $U$ within grains is typically much slower than that along grain boundaries. For simplicity, we assume that the bulk diffusion coefficients are 1000 times smaller than the grain boundary diffusion coefficients, such that the fuel grain diffusion coefficient $D_{\mathrm{fg}}=0.001 D_{\mathrm{fb}}$ and the matrix grain diffusion coefficient $D_{\mathrm{mg}}=0.001 D_{\mathrm{mb}}$. We assume that the diffusion of $U$ along a crack is 1000 times larger than that along matrix grain boundaries, such that $D_{\mathrm{c}}=1000 D_{\mathrm{mb}}$. The diffusion

\begin{tabular}{|c|c|c|c|}
\hline Function & $D_{0}\left(\frac{\mathbf{c m}^{2}}{\mathrm{~s}}\right)$ & $Q\left(\frac{\mathrm{kcal}}{\mathrm{mol}}\right)$ & Reference \\
\hline$D_{\mathrm{fb}}$ & $5.82 \times 10^{-5}$ & 72.7 & [42] \\
\hline$D_{\mathrm{mb}}$ & $3.34 \times 10^{-4}$ & 61.9 & [43] \\
\hline
\end{tabular}
coefficient within our simulation domain varies

Table III. Values used for $D_{0}$ and $Q$ in Eq. (26) along fuel and matrix grain boundaries

The cited values for $D_{\mathrm{fb}}$ and $D_{\mathrm{mb}}$ are approximated using values for $\mathrm{U}$ in $\mathrm{UO}_{2}$ and $\mathrm{W}$, respectively. 
A

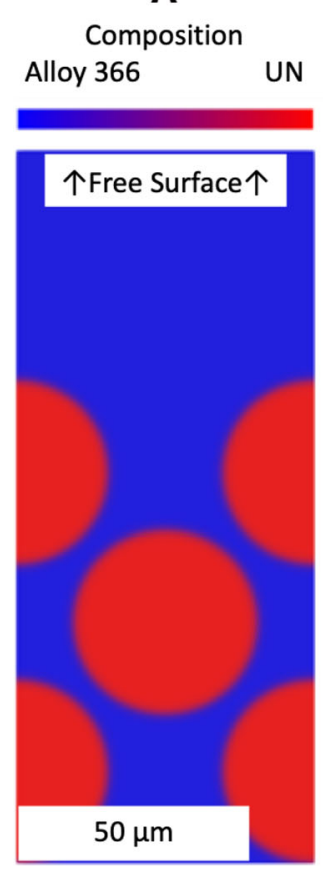

B
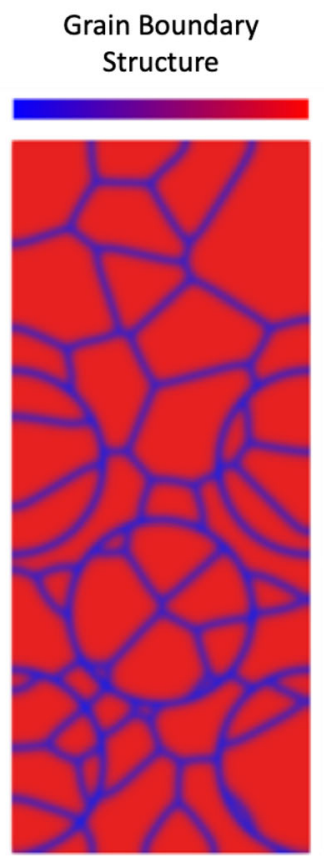

C

$$
\begin{aligned}
& D_{u}(\log \text { scale) } \\
& \begin{array}{llll}
1.56 \mathrm{e}^{-15} & 4.43 \mathrm{e}^{-13} & 7.57 \mathrm{e}^{-7} & 7.57 \mathrm{e}^{-3}
\end{array}
\end{aligned}
$$
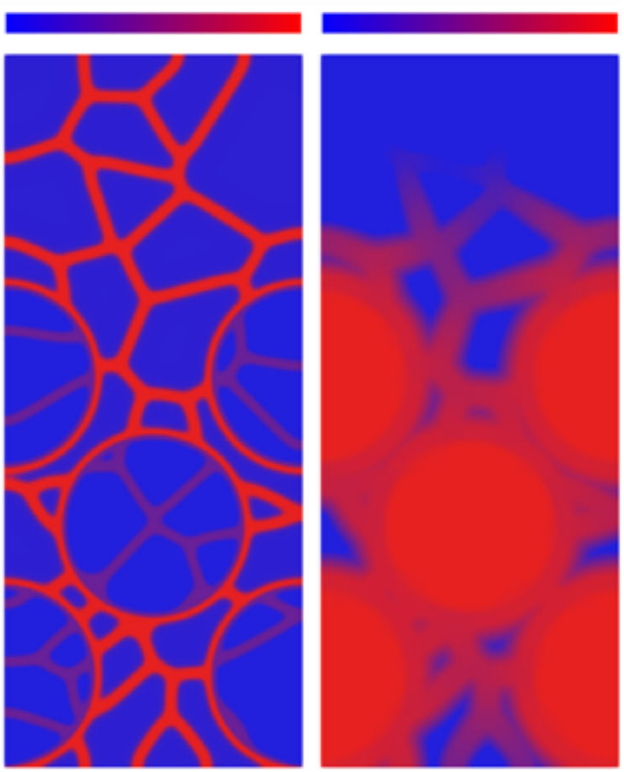

Fig. 9. A fuel loss simulation with five UN fuel particles in a matrix of Alloy 366 and a Alloy 366 cladding with a free surface on the top boundary. (A) Location of the fuel particles. (B) Grain boundary structure. (C) Diffusion coefficient throughout the microstructure, determined using Eq. (27). (D) Concentration of free $\mathrm{U}$ throughout the system after $10 \mathrm{~min}$. It is concentrated in the UN regions but also transported along the matrix grain boundaries.

spatially, depending on the values of the static fields that represent the microstructure. It is calculated according to

$$
\begin{aligned}
D_{\mathrm{U}}= & h_{\mathrm{c}} D_{\mathrm{c}}+\left(1-h_{\mathrm{c}}\right)\left[h_{\mathrm{f}}\left(1-h_{\mathrm{b}}\right) D_{\mathrm{fg}}+h_{\mathrm{f}} h_{\mathrm{b}} D_{\mathrm{fb}}\right. \\
& \left.+h_{\mathrm{m}}\left(1-h_{\mathrm{b}}\right) D_{\mathrm{mg}}+h_{\mathrm{m}} h_{\mathrm{b}} D_{\mathrm{mb}}\right] .
\end{aligned}
$$

The transport of free $U$ through the cermet microstructure is simulated by solving Eq. (24) with the finite element method using the MOOSE framework. ${ }^{38}$ We use implicit time integration to solve the partial differential equation.

\section{Fuel Loss Simulation Results}

The fuel loss model described in the previous section only approximates the behavior in a Alloy 366 -UN cermet fuel because we do not know the diffusion coefficient of U in UN and Alloy 366. Thus, it currently cannot be used to directly predict fuel loss. However, it does provide a means of investigating the impact of various aspects of the cermet fuel microstructure to assist in the optimization of fuel design.

We first demonstrate the fuel loss model using a cermet microstructure with five UN fuel particles in the Alloy 366 matrix, and an Alloy 366 cladding between the fuel and the free surface (Fig. 9A). The grain structures in the fuel particles and in the matrix were created using the Voronoi tessellation capabilities available in MOOSE, and the grain boundaries have a thickness of $2.5 \mu \mathrm{m}$ (Fig. 9B).
This is much larger than actual grain boundaries but is used to reduce the computational cost of the simulations, since the element size must be at least three times smaller than the boundary thickness. This large grain boundary thickness effectively accelerates grain boundary diffusion even more than indicated by the diffusion coefficients in the grain boundaries $\left(D_{\mathrm{mb}}\right.$ and $\left.D_{\mathrm{gb}}\right)$. For this simulation, we make the fuel intact, with no cracks. The impact of cracks is investigated next. The simulation domain is $65 \times 155 \mu \mathrm{m}$ with a mesh of $260 \times$ 620 elements. The fuel particles have a radius of 20 $\mu \mathrm{m}$, and the top $50 \mu \mathrm{m}$ is considered to be a cladding region composed of the same metal as the matrix. The top boundary has a Dirichlet boundary condition at which $x_{\mathrm{U}}=0$, acting as a free surface where the $U$ atoms are vaporized. The other three sides have zero-flux boundary conditions. The diffusion coefficient is calculated using Eq. (27) with a temperature of $2773 \mathrm{~K}$ (Fig. 9C). The simulation predicts the production, transport, and loss of free $U$ for 10 min using an adaptive time step ranging from $1 \mathrm{~s}$ to $10 \mathrm{~s}$.

The concentration of free $U$ is shown throughout the domain after $10 \mathrm{~min}$ in Fig. 9D. Free $U$ is produced due to UN decomposition in the fuel particles, so the highest concentration of free $U$ is within the fuel. However, the concentration gradient at the edge of the particles drives diffusion into the matrix. It begins to transport throughout the matrix, but due to the elevated diffusion coefficient at the grain boundaries, the largest concentrations 
are found at the grain boundaries. This is similar to what is observed in experiments (Fig. 3c). The free surface at the top of the simulation maintains the U concentration at zero. This induces a concentration gradient that drives the diffusion upward. The grain boundaries near the free surface do not have an elevated $U$ concentration because the $U$ atoms have rapidly diffused to the free surface and vaporized.

This simulation establishes the general capabilities of the fuel loss model. Free $\mathrm{U}$ is produced in the fuel particles and then diffuses toward the free surface and eventually escapes, causing fuel loss. The grain boundaries play a major role in the transport of the $U$ atoms, since they have a higher diffusion coefficient. The microstructure of the cermet fuel can be easily changed in the model, providing an avenue for investigating its impact on fuel loss.

Next, we use the fuel loss model to investigate the impact of the cermet microstructure. We model a set of simple $50 \times 100 \mu \mathrm{m} \mathrm{2D} \mathrm{microstructures} \mathrm{with} \mathrm{two}$ fuel particles embedded in a metal matrix. The fuel particles have a radius of $20 \mu \mathrm{m}$. The top surface is treated as a free surface, with the same Dirichlet boundary condition as used in the last simulation. The first particle is always in contact with the top surface and is centered horizontally in the domain. The second particle is directly below the first, and microstructures are created with different vertical distances between them; different microstructures have distances of $1 \mu \mathrm{m}, 2 \mu \mathrm{m}, 5 \mu \mathrm{m}$, and $10 \mu \mathrm{m}$. A simplified grain structure is employed in the microstructures, where the fuel particles are both evenly divided into four quarters by one vertical and one horizontal boundary. A vertical matrix grain boundary lies between the two particles, and horizontal matrix grain boundaries lie on either side of the fuel particles. Some of the microstructures also contain cracks, similar to those observed in the phase-field fracture simulations. Crack conditions include a fully cracked fuel/matrix with and without cracks along the fuel grain boundaries. Both the grain boundaries and cracks are artificially wide to decrease the computational cost of the simulation; they have a width of $2.5 \mu \mathrm{m}$. As in the previous example, this will effectively accelerate diffusion along cracks and grain boundaries beyond what is represented by the corresponding diffusion coefficient. Examples of these microstructures are shown in Fig. 10. Each simulation assumes the microstructure is at $2773 \mathrm{~K}$ and predicts the production, transport, and loss of free U. The simulation domain is represented with a mesh of $200 \times 400$ elements.

The simulation results are shown in Fig. 11. Without cracks (A and B in Fig. 11a), the highest $\mathrm{U}$ concentration is in the fuel particles. Some $U$ is present in the matrix at the interface with the fuel particles and along fuel grain boundaries due to the higher diffusion coefficient. Near the top surface, the $\mathrm{U}$ concentration is low due to vaporization at the free surface. The distance between the fuel particles does not significantly change the distribution of $U$ within the microstructure. When the fuel-matrix interface is cracked ( $\mathrm{C}$ and $\mathrm{D}$ in Fig. 11a), the U distribution in the fuel particles is relatively unchanged; however, now there is no elevated U concentration around the top particle, because it quickly transports through the crack to the top surface. This is also true for the grain boundary regions near the top particle. When the bottom particle is further from the top particle, the distribution of $U$ around it is similar to the case without the cracked interface. When the bottom particle is near the top particle, there is a rapid path for the $U$ atoms to follow to reach the top surface and there is no elevated U concentration around either particle or on any of the surrounding grain boundaries. When the interface and the fuel grain boundaries are cracked ( $\mathrm{E}$ and $\mathrm{F}$ in Fig. 11a), the U concentration in the cracks in the top fuel particle is low because the $U$ atoms can rapidly escape to the free surface. When the bottom particle is far from the top particle, there is an elevated U concentration in the cracks. When the bottom particle is near the top particle, all of the $U$ that reaches any of the cracks can rapidly reach the free surface and escape, so all the concentrations in the cracks are low.

We track the total fraction of the initial fuel lost in all the microstructures over time. In Fig. 11b, we compare the fuel loss for microstructures without cracks, those with a cracked fuel-matrix interface, and those with cracked interfaces and cracked fuel grain boundaries. When there are no cracks, the distance between the top and bottom particles has no significant impact on the fuel loss. However, with cracked interfaces, the rate of fuel loss increases with decreasing distance between the particles. When the two particles are $10 \mu \mathrm{m}$ apart, the total fuel loss after $10 \mathrm{~min}$ is 5.8 times larger with a cracked interface than without. When the particles are $1 \mu \mathrm{m}$ apart, the fuel loss is 11.2 times larger with a cracked interface. The fuel loss is even faster with cracked interfaces and fuel; the largest fuel loss with cracked interfaces is less than the smallest fuel loss with both cracked interfaces and fuel. The distance between the particles has about the same impact on fuel loss with cracked interfaces and fuel as with just cracked interfaces. When the distance between the two particles is $10 \mu \mathrm{m}$, the final fuel loss with cracked fuel and interfaces is 2.1 times larger than with just cracked interfaces. When the distance is $1 \mu \mathrm{m}$, the final fuel loss is 2.0 times larger.

Though these simulations are highly simplified compared with actual cermet fuel, they do provide useful insights into the impact of the cermet microstructure on fuel loss. Cracks have a large impact on the fuel loss, resulting in much larger fuel loss in otherwise identical microstructures. Additionally, without cracks, the distance between fuel particles in the cermet does not have a significant impact on the fuel behavior, but with cracks, the 

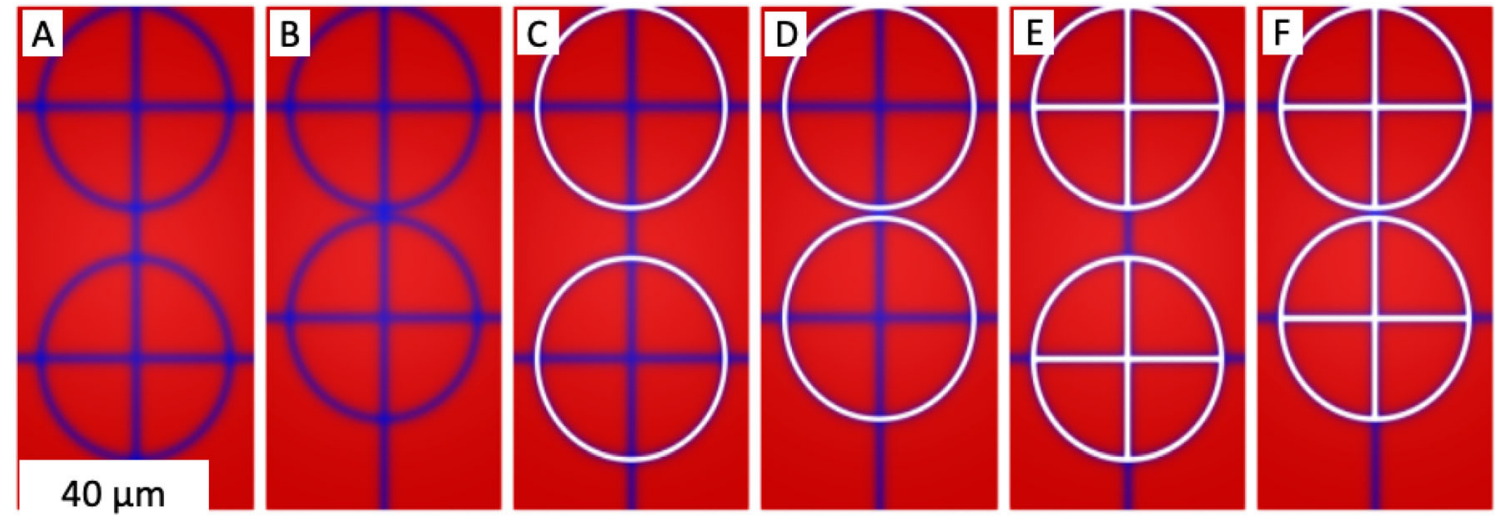

Fig. 10. Examples of the simple 2D cermet microstructures used to investigate the impact of different microstructural features on fuel loss. The fuel and matrix material is shown in red, grain boundaries in blue, and cracks in white. Uncracked microstructures with vertical distances between particles of (A) $10 \mu \mathrm{m}$ and (B) $1 \mu \mathrm{m}$, respectively. (C, D) Microstructures with cracked fuel-matrix interfaces and the same vertical distances. (E, F) Cracked interfaces and cracked fuel grain boundaries with the same distances.

\section{Free $U$}
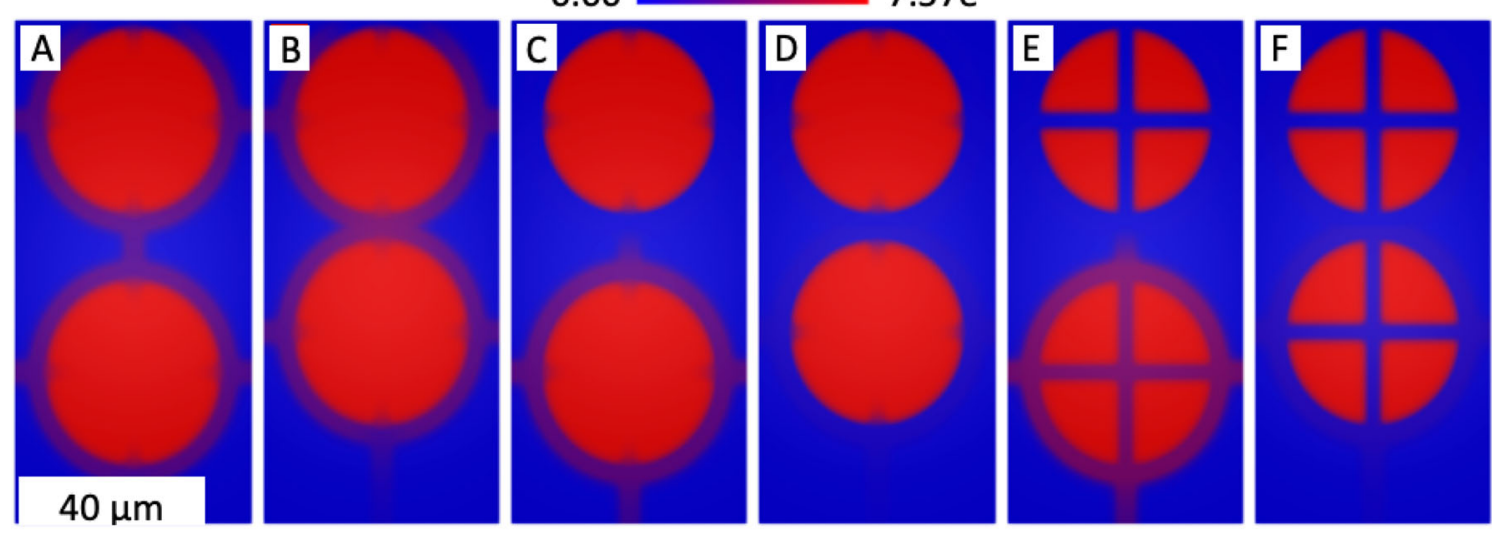

(a)

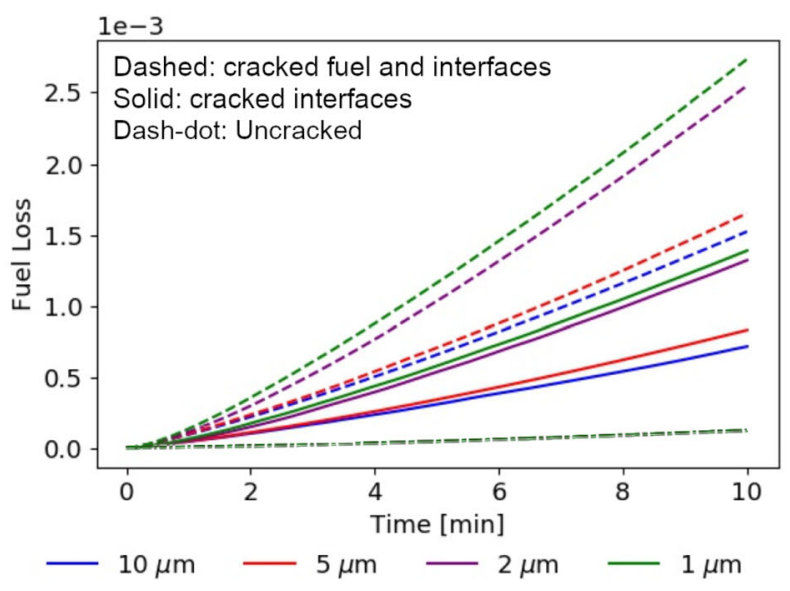

(b)

Fig. 11. Results from the two simple fuel particle simulations: (a) Free $\mathrm{U}$ concentration throughout the microstructures shown in Fig. 10 after 10 $\mathrm{min}$ at $2773 \mathrm{~K}$. (b) Comparison of the total fraction of initial fuel lost from the top surface over time for the uncracked microstructures, those with cracked interfaces, and those with cracked fuel and interfaces. 
distance does have a significant impact. Our phasefield fracture simulations show that the fuel-matrix interface could fracture even with one temperature cycle, and that the fuel grain boundaries may fracture after additional temperature cycles. The fuel loss results show that the onset of fuel fracture could accelerate fuel loss with additional temperature cycles as the fuel grain boundaries crack.

\section{DISCUSSION}

Our simple models of two phenomena that contribute to fuel loss, viz. fracture and the diffusion of free U, provide a means of exploring fuel loss. If we just consider our simple diffusion model, we can identify several ways of reducing fuel loss. Equation (26) indicates two general ways of reducing the transport of free $U$ to free surfaces: reducing the production and reducing the transport rate. To reduce the production of free $\mathrm{U}$, the high-temperature decomposition of UN must be reduced. To reduce the transport rate of free $\mathrm{U}$, we have to consider the three avenues for transport: through the grains, along grain boundaries, and along cracks. The transport of free $U$ through the fuel and matrix grains is slow and does not contribute significantly to fuel loss. Diffusion along matrix grain boundaries is significant, and reducing it will reduce fuel loss. The diffusion along cracks is the fastest, and reducing it would have the greatest impact on fuel loss.

To reduce fuel loss in UN cermets by reducing the production of free $U$, we must reduce the hightemperature decomposition that occurs in UN. ${ }^{23-25}$ As mentioned in Sect. 2, this could possibly be accomplished with additives to UN, similar to the strategy of adding oxides to $\mathrm{UO}_{2}$ to stabilize its structure. ${ }^{9}$ Adding zirconium nitride to the fuel has been shown to reduce UN decomposition, ${ }^{26,27}$ and generally any way of increasing the $\mathrm{N}$ partial pressure would reduce the decomposition. It may be possible to identify additional additives using new techniques such as high-throughput DFT calculations ${ }^{44}$ to automate the process of testing various elements to identify those that are soluble in UN and that could alter its decomposition behavior. Thermodynamic modeling could also provide a means of determining such dopants. ${ }^{17}$ Once possible elements are identified, samples would need to be fabricated and tested at high temperature to determine possible changes to the decomposition behavior.

Our simulations indicate that the most efficient way of slowing the transport of free $U$ would be to reduce cracking, both at the fuel-matrix interface and within the fuel particles. One means of reducing fracture is to reduce the strain causing fracture. The simplest way of reducing the strain is to reduce the range of temperatures experienced by the fuel by reducing the maximum temperature or increasing the minimum temperature. Reducing the maximum temperature is not desirable as it would reduce the propulsion efficiency; increasing the minimum temperature could be achieved by continually running the reactor at low power between propulsion cycles. While it is possible to change the thermal expansion in the UN fuel via additives and in the metal matrix by changing the alloying elements, it may be difficult to reduce the strain significantly in this manner without increasing neutron absorption. The strain could also be reduced via other mechanical relaxation mechanisms that were not included in our simple phase-field fracture model, such as creep. Creep occurs over time, and would only be active if the cooling rates were sufficiently slow. Another means of reducing fracture is to increase the fracture strength of the metal-matrix interface and the UN fuel kernels. Coating the fuel kernels with the metal matrix alloy, which was shown to reduce fuel loss in $\mathrm{UO}_{2}$ cermets, 9 could improve the fracture strength of the interface by improving its quality and reduce crack continuity across particles. The fracture strength of the UN could be improved using dopants; doped $\mathrm{UO}_{2}$ is more ductile than undoped $\mathrm{UO}_{2} \cdot{ }^{45}$ Viable dopants for UN would need to be identified, though DFT and other atomic-scale simulation methods could be used to identify possible dopants. ${ }^{46}$

Slowing the diffusion of $U$ through the metal matrix would also be a viable means of reducing fuel loss. One way of doing this would be to reduce the grain size of the metal matrix, increasing the diffusion length along grain boundaries for free $U$ to reach a free surface. This was accomplished in $\mathrm{UO}_{2}$ cermets using additives in the metal matrix to pin grain boundaries and reduce grain growth and using small particles to decrease the initial grain size. These same approaches should have the same effect in UN cermets, as mentioned in Sect. 2. Decreasing the grain boundary diffusion rate in the metal matrix would also slow the diffusion. Changing the alloying elements in the metal matrix could reduce the grain boundary diffusion coefficient, though it would be difficult to determine which elements would have this effect. It also could be possible to target specific crystallographic textures that have a higher concentration of grain boundaries with slower diffusion for U. Determining a means of achieving a specific texture during sintering could also be difficult.

The phase-field fracture and fuel loss simulations carried out in this work made many simplifications; we used small 2D domains with just a few fuel particles and simple grain structures, we neglected some material behaviors that occur during fuel loss, and we approximated material properties that were not available for UN and Alloy 366. Some of these approximations could be avoided in the future by using larger simulations; we can simulate larger domains, use $3 \mathrm{D}$ rather than $2 \mathrm{D}$ domains, and use more realistic microstructures. Also, additional behaviors need to be added to the fuel loss model, 
including the diffusion and reactions of hydrogen and nitrogen atoms and the formation of solid UN and $\mathrm{UH}_{3}$ along the metal matrix grain boundaries. Most importantly, efforts need to be made to obtain the missing material properties. For the phase-field fracture model, we need high-temperature mechanical testing data for UN and Alloy 366 so we can determine the single-crystal elastic constants and the single-crystal thermal expansion coefficients, so we can model the plasticity and creep behavior more accurately using constitutive models such as crystal plasticity. ${ }^{47}$ Fracture data are also needed to determine the fracture toughness of the materials. Atomic-scale and discrete dislocation dynamics simulations could also help to obtain these mechanical properties. ${ }^{17}$ For the fuel loss simulations, we need high-temperature data defining the diffusion coefficient of U through UN and Alloy 366, including bulk and grain boundary diffusion. Atomic-scale simulation could help to obtain diffusion data, as well.

The ultimate goal of our modeling the mechanisms of fuel loss at the mesoscale is to use the insights gained to develop a mechanistic model of fuel loss that could be implemented in an NTP fuel performance model. As demonstrated by Sessim and Tonks, ${ }^{11}$ a multiscale approach can be used to develop materials models for cermet fuel that are used in macroscale models of the fuel. The simple models developed in this work are too approximate to use to develop a macroscale fuel loss model at this time. However, as we obtain the missing material properties for UN and Alloy 366, we can begin to develop such a model. The NTP fuel performance model in BISON would predict the temperature and displacements throughout the fuel element. To predict fuel loss, it would also predict the evolution of the free $U$ concentration through the fuel element, with an effective diffusion coefficient and production rate in the cermet fuel that consider the microstructure and any cracking.

\section{CONCLUSIONS}

A cermet composed of UN fuel particles in a Mo-W alloy is a candidate fuel for NTP reactors to propel spacecraft for exploration of our solar system. One potential issue facing cermet fuel is fuel loss during operation. Fuel loss is well documented for $\mathrm{UO}_{2}$ cermet fuel, including successful strategies for reducing fuel loss. However, fuel loss data are rare for UN cermets. In this work, we summarize the existing understanding of fuel loss in $\mathrm{UO}_{2}$ cermets and discuss possible mechanisms for fuel loss in UN. We also show recent data for a UN cermet tested in hot hydrogen that demonstrates the occurrence of two of these mechanisms, viz. fracture of the fuel and transport of $U$ into the metal matrix.

To provide some insights into these two mechanisms, we carry out simple $2 \mathrm{D}$ mesoscale simulations. First, we model fracture in a Alloy 366-UN cermet using the phase-field fracture method. We approximate the mechanical behavior using the available data for UN and Alloy 366 and substitute the fracture and yield stresses of $\mathrm{UO}_{2}$ for $\mathrm{UN}$ and $\mathrm{W}$ for Alloy 366. Our simulation of the crack formation during thermal cycling shows that cracks form during cooling and at low temperature. They first form at the fuel-matrix interface and later within the fuel particles. We also carry out $2 \mathrm{D}$ simulations of fuel loss in which we represent a cermet microstructure and solve a diffusion equation with production of free $\mathrm{U}$ atoms within UN fuel particles. The diffusion coefficient varies across the microstructure, with different values in the fuel and the matrix, within grains and along grain boundaries, and within cracks. We approximate the diffusion coefficient in UN grain boundaries using $\mathrm{UO}_{2}$ data and in Alloy 366 grain boundaries using $\mathrm{W}$ data. We assume that the diffusion coefficient in the grains is 1000 times slower than in the grain boundaries and in cracks is 1000 times faster than in matrix grain boundaries. Our simple simulations show that cracking results in fuel loss that is 5 to 20 times faster than in a cermet without cracks. We then discuss strategies for reducing fuel loss suggested by our model results and discuss future improvements that our needed to make our models more accurate. Once they are more accurate, the mesoscale models could be used to inform the development of a fuel loss model for macroscale NTP fuel performance modeling.

\section{ACKNOWLEDGEMENTS}

This work was funded by the National Aeronautics and Space Administration's Nuclear Thermal Propulsion Program under grant no. 80NSSC19K0754 from the Marshall Space Flight Center.

\section{DATA AVAILABILITY}

The raw/processed data required to reproduce these findings cannot be shared at this time as the data also form part of an ongoing study. The raw/ processed data will be provided upon request.

\section{CONFLICT OF INTEREST}

On behalf of all authors, the corresponding author states that there are no conflicts of interest.

\section{REFERENCES}

1. J. Zhang, C. Wang, J. Zhang, D. Zhang, W. Tian, S. Qiu, and S. Guanghui, Ann. Nucl. Energy 150, 107847 (2021).

2. S.K. Bhattacharyya, An assessment of fuels for nuclear thermal propulsion. Technical Report ANL/TD/TM01-22, Argonne National Lab., IL (US), (2002).

3. R.H. Howard, and A.E. Ruggles, Nucl. Eng. Des. 361, 110516 (2020).

4. S.K. Borowski, D.R. McCurdy, and T.W. Packard, Nuclear Thermal Propulsion (NTP): A proven growth technology for human NEO/Mars exploration missions. Technical Report NASA/TM-2014-218104, National Aeronautics Space Administration (2014). 
5. R.R. Hickman, J.W. Broadway, O.R. Mireles, and N. Marshall, Space Flight, Fabrication and Testing of CERMET Fuel Materials for Nuclear Thermal Propulsion. In Proceedings of the 48th AIAA/ASME/SAE/ASEE Joint Propulsion Conference, pp 1-23, Atlanta, GA (2012).

6. L.N. Grossman, Thermal conductivity of coated particle $\mathrm{UO}_{2}$-tungsten cermets. Technical Report NASA-CR-1154. National Aeronautics and Space Administration (1968).

7. J.V. Miller, Estimating thermal conductivity of cermet fuel materials for nuclear reactor application. In Technical Report NASA-TN-D-3898, National Aeronautics and Space Administration. (Washington, DC, 1967).

8. J.L. Gustafson, Nucl. Technol. 207(6), 882 (2021).

9. C. Haertling, and R.J. Hanrahan, J. Nucl. Mater. 366(3), 317 (2007).

10. W.L. Kirk, Nuclear furnace-1 test report. Technical Report LA-5189-MS, Los Alamos Scientific. Laboratory (1973).

11. M. Sessim, and M.R. Tonks, Nucl. Technol. 207(7), 1004 (2021).

12. M.R. Tonks, D. Andersson, S.R. Phillpot, Y. Zhang, R. Williamson, C.R. Stanek, B.P. Uberuaga, and S.L. Hayes, Ann. Nucl. Energy 105, 11 (2017).

13. M.R. Tonks, D. Gaston, P.C. Millett, D. Andrs, and P. Talbot, Comput. Mater. Sci. 51(1), 20 (2012).

14. D. Schwen, L.K. Aagesen, J.W. Peterson, and M.R. Tonks, Comput. Mater. Sci. 132, 36 (2017).

15. R.L. Williamson, J.D. Hales, S.R. Novascone, M.R. Tonks, D.R. Gaston, C.J. Permann, D. Andrs, and R.C. Martineau, J. Nucl. Mater. 423(1-3), 149 (2012).

16. R.L. Williamson, J.D. Hales, S.R. Novascone, G. Pastore, K.A. Gamble, B.W. Spencer, W. Jiang, S.A. Pitts, A. Casagranda, and D. Schwen et al., Nucl. Technol. 207, 1 (2021).

17. W.C. Tucker, P. Chowdhury, L.J. Abbott, and J.B. Haskins, Nucl. Technol. 207(6), 825 (2021).

18. R.W. Ohse, J. Chem. Phys. 44(4), 1375 (1966).

19. NEXUS, NTP Materials Data Property Book. Technical report, NASA (2019)

20. D.G. Martin, J. Nucl. Mater. 152(2-3), 94 (1988).

21. V.J. Tennery, T.G. Godfrey, and R.A. Potter, J. Am. Ceram. Soc. 54(7), 327 (1971).

22. H. Matzke, J. Chem. Soc. Faraday Trans. 86(8), 1243 (1990).

23. V.V. Mikhalchik, A.V. Tenishev, V.G. Baranov, and R.S. Kuzmin, Adv. Mater. Res. 1040, 47 (2014).

24. A.V. Lunev, V.V. Mikhalchik, A.V. Tenishev, and V.G. Baranov, J. Nucl. Mater. 475, 266 (2016).

25. V.V. Mikhalchik, S.N. Nikitin, B.A. Tarasov, A.V. Tenishev, and D.P. Shornikov, KnE Mater. Sci. 4(1), 103 (2018).

26. J.K. Watkins, A. Gonzales, A.R. Wagner, E.S. Sooby, and B.J. Jaques, J. Nucl. Mater. 553, 153048 (2021).

27. J. Watkins, E. Sikorski, L. Li, and B.J. Jaques, Improved hydrothermal corrosion resistance of UN fuel forms via addition of metallic constituents. 1147 (2020).
28. J.V. Dehadraya, S.K. Mukerjee, G.A. Rama Rao, V.N. Vaidya, V. Venugopal, and D.D. Sood, J. Alloys Compd. 257(1), 313 (1997).

29. A. Sajdova, Accident-Tolerant Uranium Nitride, $\mathrm{PhD}$ Thesis, Chalmers University of Technology (2017).

30. A. Herman, and C. Ekberg, Res. Rev. J. Mater. Sci. 5(4), 83 (2017).

31. M. Ambati, T. Gerasimov, and L. De Lorenzis, Comput. Mech. 55(2), 383 (2015).

32. S. Zhang, W. Jiang, and M.R. Tonks, Comput. Methods Appl. Mech. Eng. 358, 112643 (2020).

33. A.A. Rezwan, A.M. Jokisaari, and M.R. Tonks, Comput. Mater. Sci. 194, 110407 (2021).

34. C. Miehe, M. Hofacker, and F. Welschinger, Comput. Methods Appl. Mech. Eng. 199(45), 2765 (2010).

35. P. Raffo, Yielding and fracture in tungsten and tungstenrhenium alloys. Technical Report NASA TN D-4567. In National Aeronautics and Space Administration. (Cleveland, Ohio, 1968).

36. T.S. Menshikova, F.G. Reshetnikov, V.S. Mukhin, G.A. Rymashevskii, I.G. Lebedev, and A.L. Epshtein, Soviet Atomic Energy 31(4), 1148 (1971).

37. A.G. Evans, and R.W. Davidge, J. Nucl. Mater. 33(3), 249260 (1969).

38. C.J. Permann, D.R. Gaston, D. Andrš, R.W. Carlsen, F. Kong, A.D. Lindsay, J.M. Miller, J.W. Peterson, A.E. Slaughter, R.H. Stogner et al., SoftwareX 11, 100430 (2020).

39. P. Chakraborty, Y. Zhang, and M.R. Tonks, Comput. Mater. Sci. 113, 38-52 (2016).

40. J.A. Turnbull, R.J. White, and C. Wise, The diffusion coefficient for fission gas atoms in uranium dioxide. Technical report, International Atomic Energy Agency (IAEA), IWGFPT-32 (1989).

41. C. Matthews, W.M.D. Romain Perriot, C.R. Cooper, and D.A. Andersson, J. Nucl. Mater. 540, 152326 (2020).

42. S. Yajima, H. Furuya, and T. Hirai, J. Nucl. Mater. 20, 162 (1966).

43. C.S. Su, Nucl. Inst. Methods 145, 361 (1977).

44. A. Jain, G. Hautier, C.J. Moore, S. Ping Ong, C.C. Fischer, T. Mueller, K.A. Persson, and G. Ceder, Comput. Mater. Sci. 50(8), 2295 (2011)

45. J. Arborelius, K. Backman, L. Hallstadius, M. Limbaeck, J. Nilsson, B. Rebensdorff, G. Zhou, K. Kitano, R. Loefstroem, and G. Roennberg, J. Nucl. Sci. Technol. 43(9), 967 (2006).

46. M.W.D. Cooper, C.R. Stanek, and D.A. Andersson, Acta Mater. 150, 403 (2018).

47. F. Roters, P. Eisenlohr, L. Hantcherli, D.D. Tjahjanto, T.R. Bieler, and D. Raabe, Acta Mater. 58(4), 1152 (2010).

Publisher's Note Springer Nature remains neutral with regard to jurisdictional claims in published maps and institutional affiliations. 